\title{
Single-Molecule Devices as Scaffolding for Multicomponent Nanostructure Assembly
}

\author{
Xuefeng Guo, ${ }^{a, b}$ Adam Whalley, ${ }^{a, b}$ Jennifer Klare, ${ }^{a, b}$ Limin Huang, ${ }^{b, c}$ Stephen O’Brien, ${ }^{b, c}$ \\ Michael Steigerwald, ${ }^{a, b}$ and Colin Nuckolls*a,b \\ Contributions from: \\ ${ }^{a}$ Columbia University, Department of Chemistry \\ ${ }^{b}$ The Columbia University Center for Electronics of Molecular Nanostructures \\ ${ }^{c}$ Columbia University, Department of Applied Physics/Applied Mathematics
}

\section{Synthetic Procedure for synthesis of the diaminofluorenone.}

A. General. Starting materials and reagents were obtained from commercial sources or synthesized by procedures noted below. 4-ethynyl-(N-Boc)-aniline was synthesized according to a literature procedure. ${ }^{1}$ Anhydrous and oxygen-free solvents $\left(\mathrm{CH}_{2} \mathrm{Cl}_{2}, \mathrm{Et}_{2} \mathrm{O}\right.$, THF, and toluene) were obtained from a Schlenk manifold with purification columns packed with activated alumina and supported copper catalyst (Glass Contour, Irvine, CA). ${ }^{2}$ Column chromatography was performed on a CombiFlash Sg100c system using RediSep normal phase silica columns (ISCO, Inc., Lincoln, NE). ${ }^{1} \mathrm{H}$ NMR $(300 \mathrm{MHz})$ and ${ }^{13} \mathrm{C}$ NMR $(75 \mathrm{MHz})$ were recorded on a Bruker DRX 300. ${ }^{1} \mathrm{H}$ NMR resonances were referenced to the respective solvent peak. Infrared spectra were recorded on a BioRad FTS 7000 FT-IR spectrometer using KBr plates or pellets.

\section{B. Synthesis of Boc-protected diaminofluorenone.}

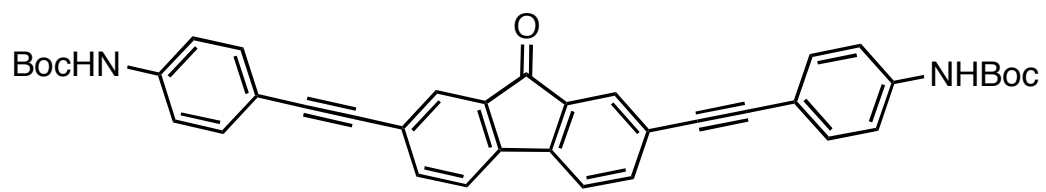

To a round bottom flask with a magnetic stir bar was added 2,7-dibromo-9-fluorenone (Aldrich, $0.250 \mathrm{~g}, 0.740 \mathrm{mmol})$, 4-ethynyl-(N-Boc)-aniline (0.354 g, $1.63 \mathrm{mmol}), \mathrm{CuI}$ (Aldrich, $0.014 \mathrm{~g}$, $0.0740 \mathrm{mmol}), \mathrm{Pd}\left(\mathrm{PPh}_{3}\right)_{2} \mathrm{Cl}_{2}$ (Strem, $\left.0.026 \mathrm{~g}, 0.037 \mathrm{mmol}\right)$, diisopropylethylamine $(5 \mathrm{~mL})$ and 
anhydrous THF $(10 \mathrm{~mL})$ under a blanket of argon. The reaction mixture was refluxed overnight. After cooling to room temperature, additional THF $(100 \mathrm{~mL})$ was added. After washing with water $(75 \mathrm{~mL} \times 2)$ and brine $(75 \mathrm{ml})$, the bright orange product was precipitated by adding hexanes. The solid was collected and washed with additional hexanes $(0.359 \mathrm{~g}, 79 \%) .{ }^{1} \mathrm{H}$ NMR (300 MHz, DMSO) $\delta 9.62(\mathrm{~s}, 2 \mathrm{H}), 7.91(\mathrm{~d}, J=7.9 \mathrm{~Hz}, 2 \mathrm{H}), 7.79(\mathrm{~d}, J=9.2 \mathrm{~Hz}, 2 \mathrm{H}), 7.71(\mathrm{~s}$, 2H), $7.54(\mathrm{~d}, J=8.8 \mathrm{~Hz}, 4 \mathrm{H}), 7.48(\mathrm{~d}, J=8.9 \mathrm{~Hz}, 4 \mathrm{H}), 1.49(\mathrm{~s}, 18 \mathrm{H}) \mathrm{ppm} ;{ }^{13} \mathrm{C} \mathrm{NMR}(75 \mathrm{MHz}$ DMSO) $\delta 153.4,143.6,141.3,138.9,134.7,133.1,127.2,124.7,123.0,118.8,88.5,80.4,28.9$ ppm; FTIR (thin film): 3356, 2980, 2928, 2204, 1715, 1584, 1523, 1407, 1311, 1230, 1158, 1055, $834 \mathrm{~cm}^{-1}$. HRMS (FAB+, [M+]) calcd for $\mathrm{C}_{39} \mathrm{H}_{34} \mathrm{O}_{5} \mathrm{~N}_{2} 610.2468 \mathrm{~m} / z$; found $610.2458 \mathrm{~m} / \mathrm{z}$.

\section{Synthesis of the diaminofluorenone.}

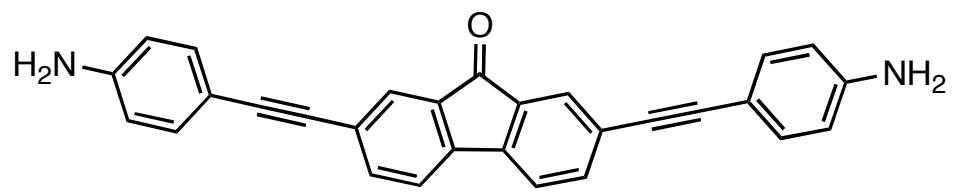

The Boc-protected diaminofluorenone $(0.015 \mathrm{~g}, 0.025 \mathrm{mmol})$ was dissolved in a mixture of $3 \mathrm{~mL}$ $\mathrm{CH}_{2} \mathrm{Cl}_{2}$ and $3 \mathrm{~mL}$ of TFA and stirred at room temperature for two hours. Removal of the solvent and acid in vacuo resulted in a white solid $(0.010 \mathrm{~g}, 97 \%)$.

${ }^{1} \mathrm{H}$ NMR (300 MHz, DMSO) $\delta 7.85(\mathrm{~d}, J=7.7 \mathrm{~Hz}, 2 \mathrm{H}), 7.71(\mathrm{~d}, J=9.1 \mathrm{~Hz}, 2 \mathrm{H}), 7.63(\mathrm{~s}, 2 \mathrm{H})$, $7.30(\mathrm{~d}, J=8.1 \mathrm{~Hz}, 4 \mathrm{H}), 6.69(\mathrm{~d}, J=7.3 \mathrm{~Hz}, 4 \mathrm{H}) \mathrm{ppm} ;{ }^{13} \mathrm{C}$ NMR $(75 \mathrm{MHz}, \mathrm{DMSO}) \delta 191.7$, $147.6,142.3,137.5,133.8,134.7,132.8,125.9,124.4,121.8,115.0,93.2,86.6$ ppm; FTIR (KBr pellet): $3441,2922,1675,1512,1201,1135,830 \mathrm{~cm}^{-1}$.

\section{Rejoining and functionalization of molecular devices from SWNTs.}

Table S1. The ON-state resistance of the devices before and after reconnection used to estimate the molecular resistance.

$\mathrm{R}$ before cut $\quad \mathrm{R}$ after reconnection

1

2

3 $\sim 5.40 \times 10^{6} \Omega$

$\sim 3.97 \times 10^{5} \Omega$

$\sim 8.33 \times 10^{7} \Omega$ $\sim 6.49 \times 10^{8} \Omega$

$\sim 2.00 \times 10^{8} \Omega$

$\sim 7.05 \times 10^{8} \Omega$
$\mathrm{R}$ for molecule

$\sim 6.44 \times 10^{8} \Omega$

$\sim 2.00 \times 10^{8} \Omega$

$\sim 6.22 \times 10^{8} \Omega$ 


$\begin{array}{llll}4 & \sim 1.95 \times 10^{5} \Omega & \sim 4.95 \times 10^{8} \Omega & \sim 4.95 \times 10^{8} \Omega \\ 5 & \sim 8.03 \times 10^{5} \Omega & \sim 8.08 \times 10^{7} \Omega & \sim 8.00 \times 10^{7} \Omega \\ 6 & \sim 2.86 \times 10^{5} \Omega & \sim 3.50 \times 10^{6} \Omega & \sim 3.21 \times 10^{6} \Omega \\ 7 & \sim 1.67 \times 10^{6} \Omega & \sim 1.66 \times 10^{7} \Omega & \sim 1.49 \times 10^{7} \Omega \\ 8 & \sim 3.78 \times 10^{5} \Omega & \sim 2.59 \times 10^{6} \Omega & \sim 2.21 \times 10^{6} \Omega\end{array}$

\section{Functionalization of the reconnected devices}

A. General. N-(aminooxyacetyl)-N'-(D-diotinoyl)hydrazine, trifluoroacetic acid salt (ARP) is available from Molecular Probes. Bovine serum albumin is available from EQUITECH-BIO. Inc. Streptavidin is commercial from PIERCE Biotechnology. Streptavidin-conjugated gold nanoparticles ( $5 \mathrm{~nm}$ diameter on average) is commercial from TED Pella, Inc..

B. Oximation of the rejoined devices. N-(aminooxyacetyl)-N'-(D-diotinoyl)hydrazine, trifluoroacetic acid salt $(5 \mathrm{mg})$ was dissolved in anhydrous pyridine $(10 \mathrm{~mL})$ under $\mathrm{N}_{2}$ at room temperature, and then the rejoined devices were immersed to this solution overnight. ${ }^{3}$ After the reaction, the devices were washed by acetone, isopropanol, deionized water and dried with a stream of $\mathrm{N}_{2}$ gas.

C. Attachment of Streptavidin to the devices. Soaking the devices from above into the original buffer (tris buffered saline) solution of streptavidin $(28 \mu \mathrm{g} / \mathrm{mL})$ or streptavidinconjugated gold nanoparticles $((28 \mu \mathrm{g} / \mathrm{mL})$ for $1 \mathrm{~h}$. And then removed, washed by acetone, isopropanol, deionized water, and dried with a stream of $\mathrm{N}_{2}$ gas.

\section{Current-Voltage Curves for Control Experiments}




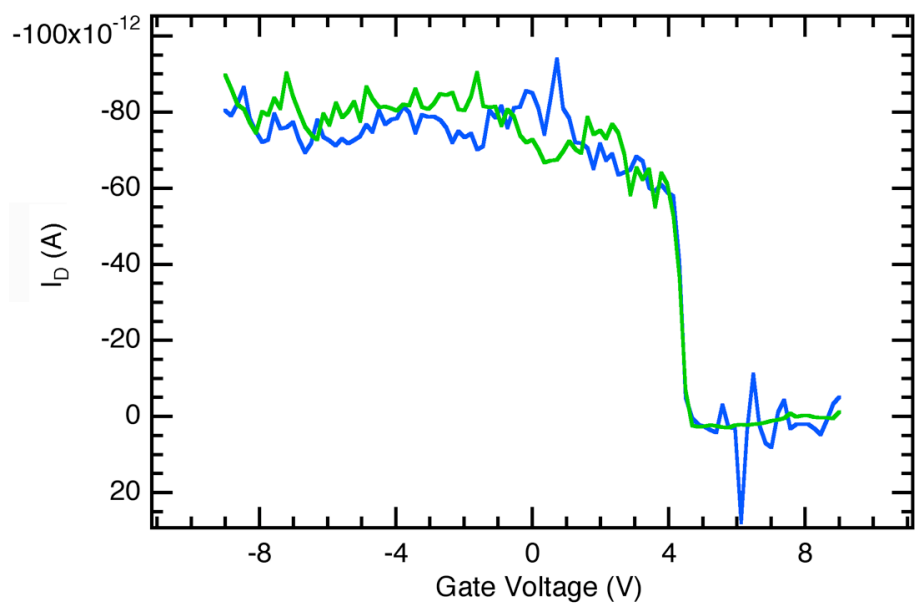

Figure S1. Control experiment testing the effect of solvent. Gate voltage versus drain current in a semiconducting SWNT device reconnected with the diaminofluorenone (green trace) compared to the data after immersion in pyridine, removal, and drying (blue trace).

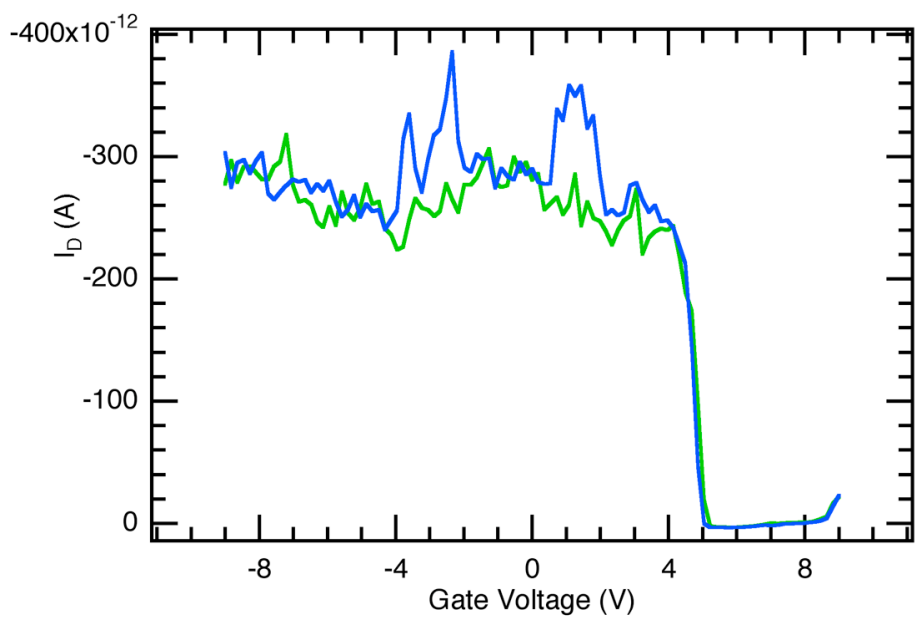

Figure S2. Control experiment testing the need for the biotin component to carry an alkoxylamine functionality. Gate voltage versus drain current in a semiconducting SWNT device reconnected with the diaminofluorenone (green trace) compared to the data after immersion in a pyridine solution of unfunctionalized biotin, removal, and drying (blue trace). 


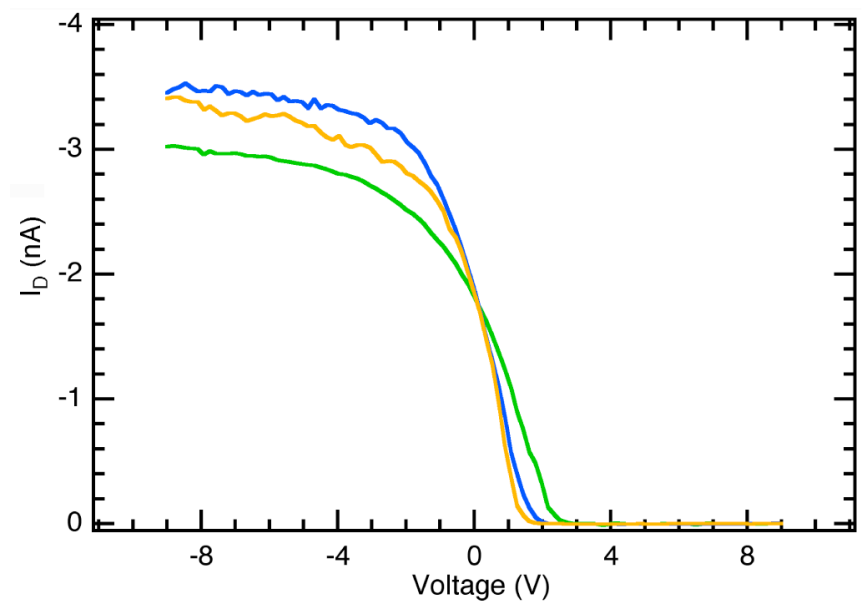

Figure S3. Control experiment testing for specificity between ligand and protein. Gate voltage versus drain current in a semiconducting SWNT device reconnected with the diaminofluorenone (green trace), after reaction with the biotin alkoxyamine (blue trace), and immersion in a solution of bovine serum albumin (BSA) (yellow trace).

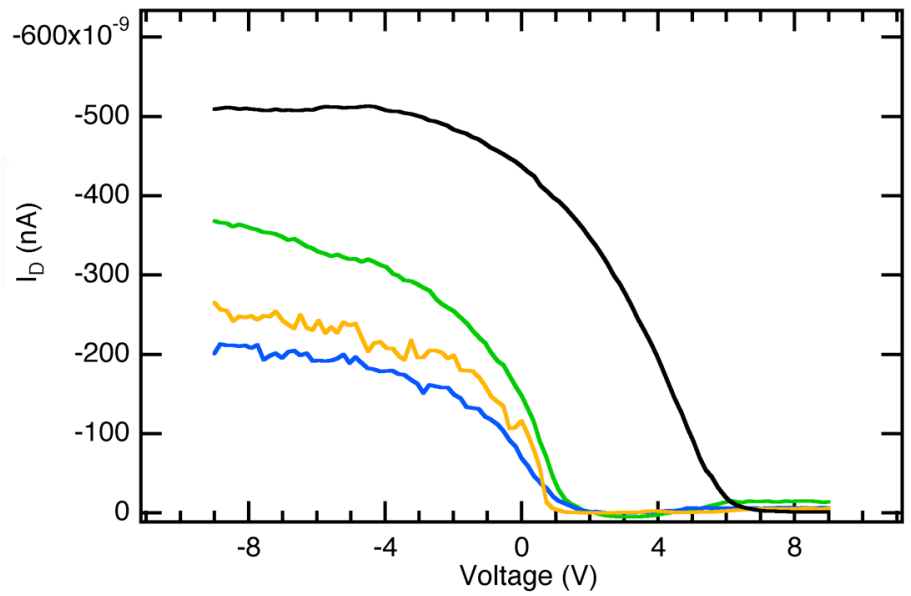

Figure S4. Control experiment testing tubes which were only partially cut by the oxygen plasma. Gate voltage versus drain current in a semiconducting SWNT device before treatment with an oxygen plasma (black trace); device after treatment with an oxygen plasma and then reacted with the diaminofluorenone (green trace); device after reaction with the biotin alkoxyamine (blue trace), and immersion in a solution of streptavidin (yellow trace). 


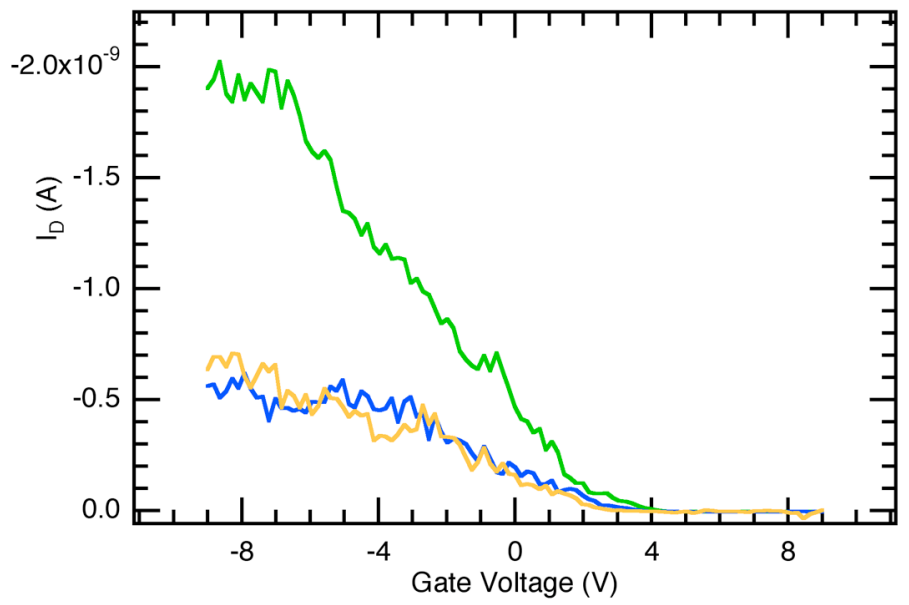

Figure S5. Control experiment testing tubes which were NOT treated with the oxygen plasma. Gate voltage versus drain current in a semiconducting SWNT that was not exposed to the oxygen plasma but put in a solutin of the diaminofluorenone (green trace); device after reaction with the biotin alkoxyamine (blue trace), and immersion in a solution of streptavidin (yellow trace).

\section{DFT experimental section.}

DFT calculations were performed using Jaguar 6.0, Schrödinger, L.L.C., Portland, OR, 19912006.

All calculations used the B3LYP functional and $6-31 \mathrm{G}^{* *}$ basis sets. The geometries of fluorenone, fluorenone-methyloxime and the 4,4' diamine and diamide (-NHCHO) compounds were fully optimized. Details of the geometries are available on request.

In order to model the effect of streptavidin binding on the energetics of the fluorenone oxime, we artificially fixed the $\mathrm{CNO}$ and $\mathrm{NCO}$ angles and allowed subsequent geometry optimization. The energies of the arene HOMO changed only slightly. Similarly, variation of the CNOC dihedral angle changes the HOMO energy only slightly.

\begin{tabular}{|c|c|c|c|c|}
\hline Molecule & $\begin{array}{l}\mathrm{E}(\mathrm{HOMO}) \\
\mathrm{h}\end{array}$ & $\begin{array}{l}\mathrm{E}(\text { LUMO), } \\
\mathrm{h}\end{array}$ & $\begin{array}{l}\mathrm{E}(\mathrm{HOMO})-\mathrm{E}(\mathrm{LUMO}), \\
\mathrm{mh}\end{array}$ & $\begin{array}{l}\text { Calculated } \\
\text { dipole moment, D }\end{array}$ \\
\hline fluorenone & -0.22920 & -0.08201 & 147.19 & 3.4 \\
\hline fluorenone-methyl oxime & -0.21691 & -0.06260 & 154.31 & 0.5 \\
\hline fluorenone - 4,4'-diamine & -0.18032 & -0.06843 & 111.89 & 3.4 \\
\hline $\begin{array}{l}\text { fluorenone-methyl oxime - } \\
4,4^{\prime} \text {-diamine }\end{array}$ & -0.17153 & -0.05064 & 120.89 & 2.3 \\
\hline fluorenone - 4,4'-diamide & -0.20944 & -0.08282 & 126.62 & 9.4 \\
\hline $\begin{array}{l}\text { fluorenone-methyl oxime - } \\
4,4^{\prime} \text {-diamide }\end{array}$ & -0.19904 & -0.06361 & 135.43 & 5.0 \\
\hline
\end{tabular}

\section{References and Notes.}

1. Zhang, J.; Podoprygorina, G.; Brusko, V.; Boehmer, V.; Janshoff, A. Chem. Mater. 2005, $17,2290$. 
2. Pangborn, A. B.; Giardello, M. A.; Grubbs, R. H.; Rosen, R. K.; Timmers, F. J. Organomet. 1996, 15, 1518.

3. Blake, J. A.; Pratt, D. A.; Lin, S.; Walton, J. C.; Mulder, P.; Ingold, K. U. J. Org. Chem. 2004, 69, 3112. 